American J. of Engineering and Applied Sciences 1 (3): 223-229, 2008

ISSN 1941-7020

(C) 2008 Science Publications

\title{
Leveling Process of Total Electron Content (TEC) Using Malaysian Global Positioning System (GPS) Data
}

\author{
${ }^{1}$ Norsuzila, Y., ${ }^{1,2} \mathrm{M}$. Abdullah and ${ }^{1,2} \mathrm{M}$. Ismail \\ ${ }^{1}$ Department of Electrical, Electronic and Systems Engineering, \\ Universiti Kebangsaan Malaysia, 43600 UKM Bangi, Selangor, Malaysia \\ ${ }^{2}$ Institute of Space Science, Universiti Kebangsaan Malaysia, 43600 UKM Bangi, Selangor, Malaysia
}

\begin{abstract}
The signals from the satellites of the Navstar Global Positioning System (GPS) travel through the earth's ionosphere on their way to GPS receivers. However, ionospheric delay is one of the main sources of error in GPS. The magnitude of the ionospheric delay is influenced by the Total Electron Content (TEC) along the radio wave path from a GPS satellite to the ground receiver. This study investigates the TEC using GPS data collected from Wisma Tanah, Kuala Lumpur, KTPK $\left(3^{\circ} 10^{\prime} 15.44^{\prime} \mathrm{N}, 101^{\circ} 43^{\prime} 03.35^{\prime \prime} \mathrm{E}\right)$ station and processed and analyzed under quiet geomagnetic day at the equatorial region on 8 November 2005. This research assesses the errors translated from the code-delay to the carrier-phase ionospheric observable by the so-called leveling process, which was applied to reduce multipath from the data. It was found that the leveled carrier-phase ionosphere observable was affected by a systematic error, produced by code-delay multipath through the leveling procedure. The effects, however, do not cancel after averaging all the data. Dual frequency carrierphase and code-delay GPS observations are combined to obtain ionospheric observable related to the slant TEC (TECs) along the satellite-receiver line of sight (los). This results in the absolute differential delay and the remaining noise was discarded. These are the first results obtained using TEC-GPS technique for TEC measurement in Malaysia.
\end{abstract}

Key words: Slant TEC (TECs), line of sight (los), vertical TEC (TECv), GPS, ionosphere

\section{INTRODUCTION}

Earlier researches on the ionosphere were carried out using satellite beacon signals received from geosatellites and radio sounding systems such as radars, probes and ionosonde. The advent of Global Positioning System (GPS) technology provides a low cost solution for monitoring the ionosphere on a global basis. Application of GPS for ionospheric sensing is now being the subject of worldwide interest.

The ionosphere is a dispersive medium for electromagnetic waves. The regular refraction of a radio signal passing through the ionosphere can be calculated provided that the ionosphere has a symmetric distribution of electron density, the radio signal frequency is substantially above the F- layer's critical frequency and the layer thickness is substantially smaller than its radius of curvature. Refraction then will depend on the radio signals frequency, on the Total Electron Content (TEC) of the ionosphere and on the angle of incidence of the radio wave in the ionospheric layer.

Prediction and assessment of transionospheric propagation errors is necessary for precise measurements. It contributes valuable information to satellite and space probe navigation, space geodesy, radio astronomy and others. An ionospheric error correction model should be made applicable at any location including the equatorial region. Zain et al. ${ }^{[1]}$ have reported on analysis of TEC using the GPS station at Arau, Perlis, in the northern part of Malaysia. Short term TEC analysis was also done using GPS station at Miri, Sarawak ${ }^{[2]}$. While Ho et al. ${ }^{[3]}$ has reported on typical hourly variations for quiet ionosphere over Malaysia for $24 \mathrm{~h}$ on July 14, 2000.

This study is to clarify the GPS performance to determine the absolute vertical Total Electron Content (TECv) from dual frequency GPS measurements and to apply the dual frequency method, mapping functions, Single Layer Model (SLM) and modified single layer

Corresponding Author: Norsuzila Ya'acob, Department of Electrical, Electronic and Systems Engineering,

Universiti Kebangsaan Malaysia, 43600 UKM Bangi, Selangor, Malaysia

Tel: +0193330864 Fax: +60389216304 
model (M-SLM). Then the ionospheric delay is calculated using leveling technique of phase measurements.

\section{MATERIALS AND METHODS}

Total Electron Content (TEC): The earth's ionosphere which causes problems in radio applications, especially for navigation, is now the subject of active research. Solar activity such as flares and Coronal Mass Ejections (CMEs) often produces large variations in the particle and electromagnetic radiation above the earth. The perturbations cause large disturbances in Total Electron Content (TEC) and ionospheric current system. The TEC measurements obtained from dual frequency GPS receivers are one of the most important methods of investigating the earth's ionosphere.

The largest TEC enhancement occurred at the subsolar region (Africa equatorial GPS station), with TEC increases of 22 TECU above the background ${ }^{[4]}$. Most recently, Fedrizzi et al. ${ }^{[5]}$ also used the same model to study TEC variability associated with geomagnetic storm activity over locations in the South American Sector. There are many techniques used to probe the ionosphere that includes the earth based radio techniques: vertical sounders, incoherent scatter radar, etc., as well as space-based techniques: Geostationary satellites, GPS satellites, LEO satellites and in situ measurements. Ionospheric scientists are also using new techniques such as computed tomography $y^{[6-8]}$, occultation $^{[9,10]}$ and University of New Brunswick (UNB) ionospheric modeling technique ${ }^{[11]}$.

The electron density in the ionosphere varies with geographic latitude, season, solar cycle and time of day. During quiet solar activity, the daytime maximum TEC occurs around noon and past noon local time while the minimum TEC occurrence is post midnight. A dualfrequency GPS receiver measures pseudoranges and carrier phases at L1 (1575.42 MHz) and L2 (1227.60 $\mathrm{MHz}$ ) and its observables are used to compute TEC. The differential time delay measurements are used to remove the ambiguity term.

GPS can be used to measure the TEC by utilizing dual frequency data forming the linear combination, L4 (geometry-free LC). In the case of code observation, the TEC is proportional to the difference of the ionospheric time delay on two frequencies. For the phase observations, the method is influenced by an unknown differential ambiguity term. This ambiguity can be estimated together with ionospheric model parameters or scaled to the code pseudorange but multipath effects must also be taken into account.
A GPS operates on two different frequencies $f_{1}$ and $\mathrm{f}_{2}$, which are derived from the fundamental frequency of $=10.23 \mathrm{MHz}$ :

$$
\begin{aligned}
& \mathrm{f}_{1}=154 . \mathrm{fo}=1575.42 \mathrm{MHz} \text { and } \\
& \mathrm{f}_{2}=120 . \mathrm{fo}=1227.60 \mathrm{MHz}
\end{aligned}
$$

Both code and phase measurements are affected by the dispersive behavior of the ionosphere, but with different leading signs, which the absolute value of the group delay can be written as:

$$
\mathrm{I}_{\phi, \mathrm{g}}=\int \frac{\mathrm{X}}{2} \mathrm{ds}=\frac{80.6}{2 \mathrm{f}^{2}} \int \mathrm{N}_{\mathrm{e}} \mathrm{ds}
$$

This delay is characterized by the total electron content where TEC $=\int \mathrm{N}_{\mathrm{e}} \mathrm{ds}$. Substituting TEC into (2) yields

$$
\begin{aligned}
\mathrm{I}_{\phi, \mathrm{g}} & =\frac{40.3}{\mathrm{f}^{2}} \text { TEC }[\mathrm{m}] \text { or } \\
\Delta \mathrm{t} & =\frac{40.3}{\mathrm{cf}^{2}} \text { TEC }[\mathrm{s}]
\end{aligned}
$$

These delays can be expressed in units of distance or time delay by dividing the right hand side of the Eq. (3) that measured in meters by the velocity of light.

A dual-frequency GPS receiver can measure the difference in ionospheric delays between the L1 $(1575.42 \mathrm{MHz})$ and L2 $(1227.60 \mathrm{MHz})$ of the GPS frequencies, which are generally assumed to travel along the same path through the ionosphere. Thus, the group delay can be obtained from (3) as:

$$
\mathrm{P}_{1}-\mathrm{P}_{2}=40.3 \operatorname{TEC}\left(\frac{1}{\mathrm{f}_{2}^{2}}-\frac{1}{\mathrm{f}_{1}^{2}}\right)
$$

Where, $\mathrm{P}_{1}$ and $\mathrm{P}_{2}$ are the group path lengths corresponding to the high GPS frequency $\left(f_{1}=\right.$ $1575.42 \mathrm{MHz})$ and the low GPS frequency $\left(\mathrm{f}_{2}=1227.6\right.$ $\mathrm{MHz}$ ), respectively.

Carrier phase leveling process: GPS signals can be used to extract ionospheric parameters such as TEC. It is represented by a third degree polynomial where the coefficients of the polynomial are transmitted as part of the broadcast message header. The TEC can also be obtained by writing (4) as:

$$
\mathrm{TEC}=\frac{1}{40.3}\left(\frac{\mathrm{f}_{1}^{2} \mathrm{f}_{2}^{2}}{\mathrm{f}_{1}^{2}-\mathrm{f}_{2}^{2}}\right)\left(\mathrm{P}_{2}-\mathrm{P}_{1}\right)
$$


if dual frequency receiver measurements are available.

The TEC data derived from GPS pseudorange measurements have a large uncertainty because of the pseudorange has high noise level. In contrast, the noise level of carrier phase measurements is significantly lower than the pseudorange ones. To reduce the effect of pseudorange noise on TEC data, GPS pseudorange data can be smoothed by carrier phase measurements. For example by using carrier phase smoothing technique, which is also often referred to as carrier phase leveling.

\section{Parameters of the study}

Slant TEC: The Slant TEC (TECs) is a measure of the total electron content of the ionosphere along the ray path from the satellite to the receiver, shown in Fig. 1. It can be calculated by using pseudorange and carrier phase measurements as in Eq. (5). As slant TEC is a quantity which is dependent on the ray path geometry through the ionosphere, it is desirable to calculate an equivalent vertical value of TEC which is independent of the elevation of the ray path.

If both the differential carrier phase and the differential group delay are measured with a dualfrequency GPS receiver, the user can easily obtain both the absolute TEC and its rate of change.

Vertical TEC: The vertical TEC (TECv) is the main interest in the ionosphere research. Therefore, the TECs obtained from GPS observable are converted to vertical using a suitable mapping function. However, it is the conversion that introduces the error. This conversion introduces a few errors in the middle latitude where electron density is small. But it may result in obvious errors at low latitude with large electron density and great gradient $^{[12]}$. In order to refer to? the vertical TEC, the single layer thin-shell model was employed to determine the absolute vertical TEC (TECv).

Mapping functions: The TEC measurements were estimated by assuming that the ionosphere is a spherical shell at fixed height of $400 \mathrm{~km}$ above the earth's surface. The sampling rate of each GPS receiver is 15 sec. The slant TEC is then converted to vertical TEC using the obliquity correction factor. The point where the TECv is determined is called the Ionospheric Pierce Point (IPP), which is the intersection of the user line of sight to the tracked satellite with the center of the ionospheric slab as shown in Fig. $1^{[13]}$.

Generally by referring to Fig. 1, TECs is obtained through a given sub-ionospheric point from:

$$
\mathrm{TEC}=\mathrm{TEC}_{\mathrm{S}} \cos \chi^{\prime}
$$

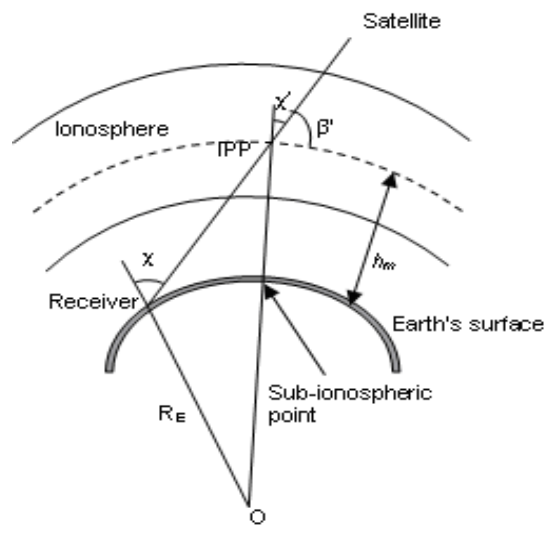

Fig. 1: Ionospheric single layer model

The thin shell model mapping function, SLM where (6) can be written as:

$$
\begin{aligned}
\mathrm{F}(\chi) & =\frac{\operatorname{TEC}(\chi)}{\operatorname{TEC}(0)} \\
& =\frac{1}{\cos \chi^{\prime}\left(\operatorname{or} \sin \beta^{\prime}\right)} \\
& =\frac{1}{\sqrt{1-\sin ^{2} \chi^{\prime}}}
\end{aligned}
$$

with

$$
\sin \chi^{\prime}=\frac{\mathrm{R}_{\mathrm{E}}}{\mathrm{R}_{\mathrm{E}}+\mathrm{h}_{\mathrm{m}}} \times \sin \chi
$$

Where:

$\mathrm{R}_{\mathrm{E}} \quad=$ The mean earth radius

$\mathrm{h}_{\mathrm{m}} \quad=$ The height of maximum electron density

$\chi$ and $\chi^{\prime}=$ The zenith angles at the receivers site and at the ionospheric pierce point IPP

Typical value for $R_{E}$ and $h_{m}$ are set to 6371 and $450 \mathrm{~km}$, respectively. The mapping function below is modified single layer model, M-SLM which is defined as:

$$
\sin \chi^{\prime}=\frac{\mathrm{R}_{\mathrm{E}}}{\mathrm{R}_{\mathrm{E}}+\mathrm{h}_{\mathrm{m}}} \times \sin (\alpha \chi)
$$

where $\alpha$ is correction factor which is close to unity.

\section{RESULTS AND DISCUSSION}

The ionosphere GPS-TEC measurements were carried out using GPS receiver networks from Jabatan 
Ukur dan Pemetaan Malaysia (JUPEM). A GPS data on 8 November 2005 were analyzed for this initial analysis at Wisma Tanah, Kuala Lumpur, KTPK station. This analysis was based on $1 \mathrm{~h}$ observations from 1-2 (UT) using GPS satellite PRN 3, 4-5 (UT) using GPS satellite PRN 23 and 22-23 (UT) using GPS satellite PRN 15. The GPS data was recorded in GPS time system. The sampling time interval is $15 \mathrm{sec}$ and the cut-off elevation mask is $15^{\circ}$. GPS data used in this project were recorded on a quiet geomagnetic day where the geomagnetic index, $\mathrm{Kp}$ is 1 .

Figure 2-6 show representative cases of the different situations found in the analysis. The absolute slant TEC from the KTPK station can be measured directly from this dual frequency method. This can be calculated by using pseudorange and carrier phase measurements from the satellites (e.g., PRN 3, 23 and 15) used in this study. Figure 2 shows the elevation angle of GPS satellite PRN 3, PRN 23 and 15 for KTPK Station. The elevation angle can be calculated from the GPS navigation data (or ephemeris).

The plots in Fig. 3a, b and c are different phase before they were scaled to different code $\left(\mathrm{P}_{2}-\mathrm{C}_{1}\right)$ in meters. It clearly indicates the relative differential carrier phase on a relative scale. The differential delay $\left(\mathrm{P}_{2}-\mathrm{C}_{1}\right)$ from code measurements was noisy and influenced by multipath. The phase measurements were ambiguous, so the phase derived slant delay was scaled to zero relative range error at the first epoch. This eliminates the integer ambiguity provided there are no cycle slips.

Shown in Fig. 4 are the absolute ionospheric range error obtained from differential group delay. At this stage, leveling process was applied to eliminate the code multipath effect especially at low elevation angles. This was done by defining a shift value and adding it to the relative phase to fit the code differential delay. For the leveling process, it assumed the average at the elevation angle $\left( \pm 60-90^{\circ}\right)$ as reference and it can be shown in Fig. 2. This value was chosen because there is no multipath at the high elevation angle and during low elevation angle multipath where it can still be seen. After the differential carrier phase was converted to an absolute scale by fitting it to the differential group delay curve over the desirable, low multipath portion of each pass, the differential group delay data were simply discarded.

This smoothed differential delay (with less noise and multipath) was then translated to the absolute slant TEC by multiplying it by a constant (Eq. 5) as shown in Fig. 5. The final TEC values are precise, accurate and without multipath, unless the multipath environment is really terrible, in which case a small, residual amount of

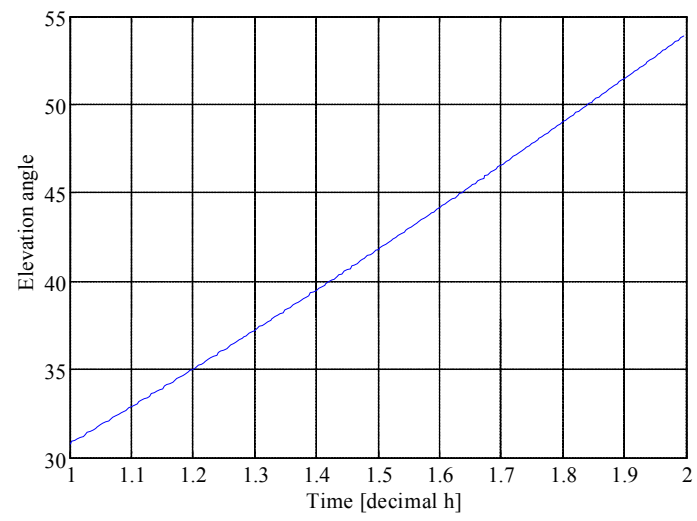

\section{1-2 (UT) GPS Satellite PRN 3}

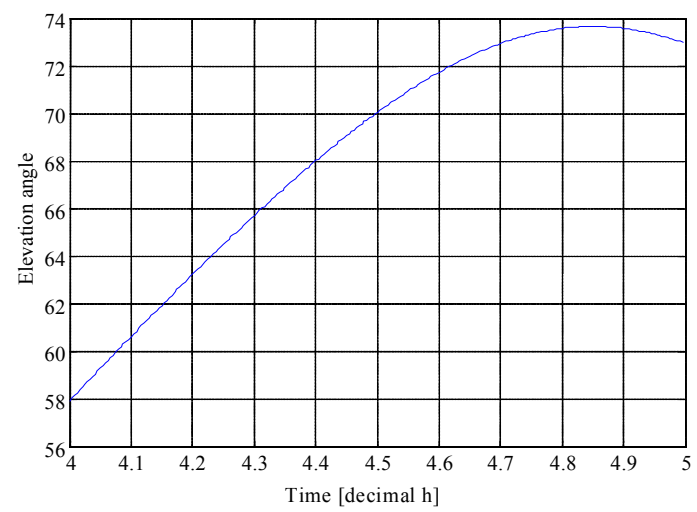

4-5 (UT) GPS Satellite PRN 23

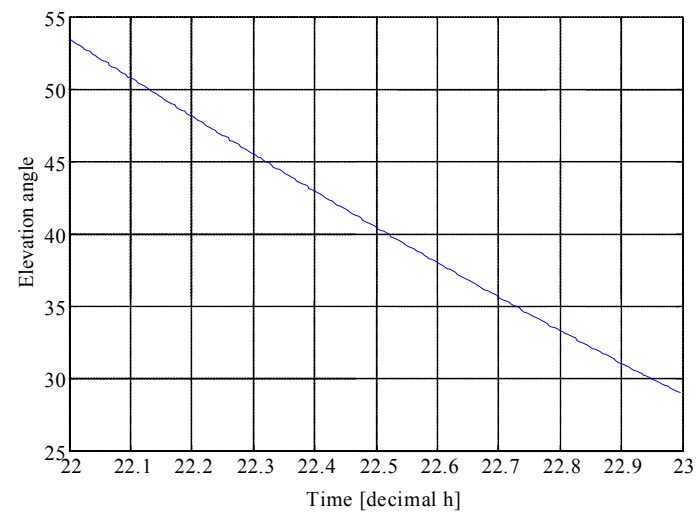

22-23(UT) GPS Satellite PRN 15

Fig. 2: Elevation angle of GPS Satellite PRN 3 (top), PRN 23 (middle) and PRN 15 (bottom) for KTPK Station

multipath can even be seen in the differential carrier phase. 


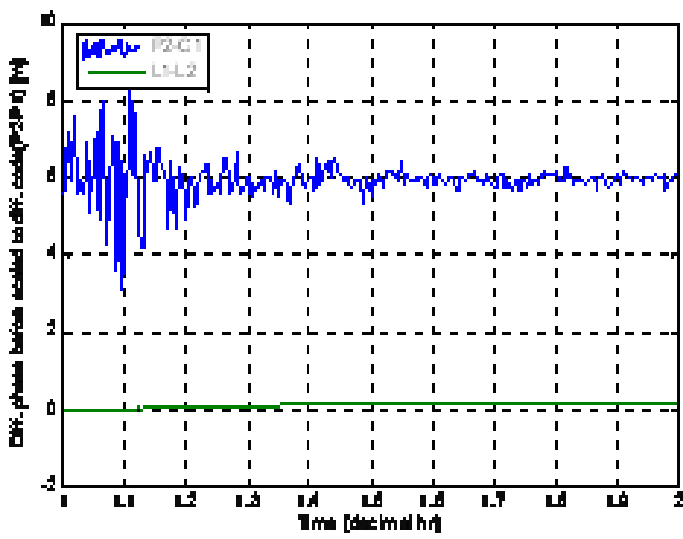

1-2 (UT) GPS Satellite PRN 3

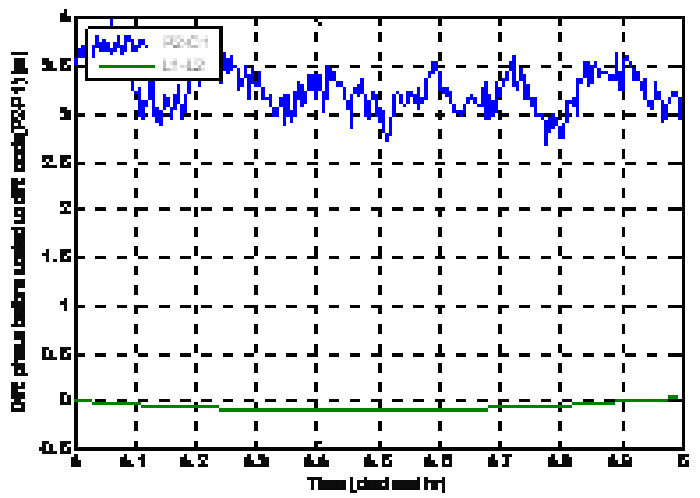

4-5 (UT) GPS Satellite PRN 23

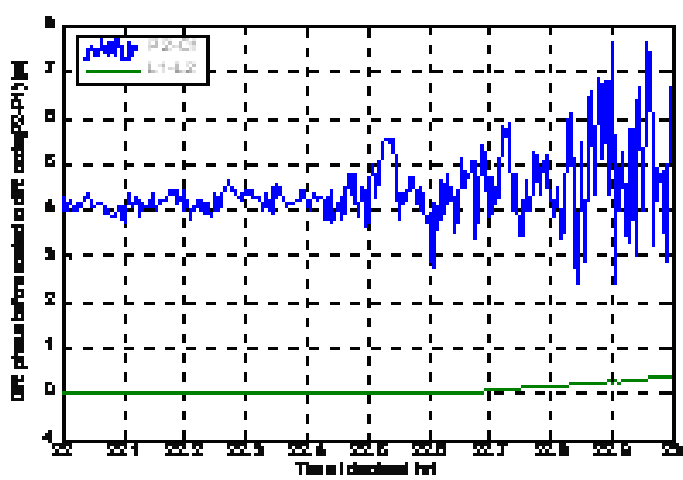

22-23 (UT) GPS Satellite PRN 15

Fig. 3: Different phase (L1-L2) before scale to different code (P2-C1) for GPS Satellite PRN 3 (top), PRN 23 (middle) and PRN 15 (bottom) for KTPK Station.

A mapping function, Single Layer Model (SLM), was used to convert TEC to the vertical TEC from the

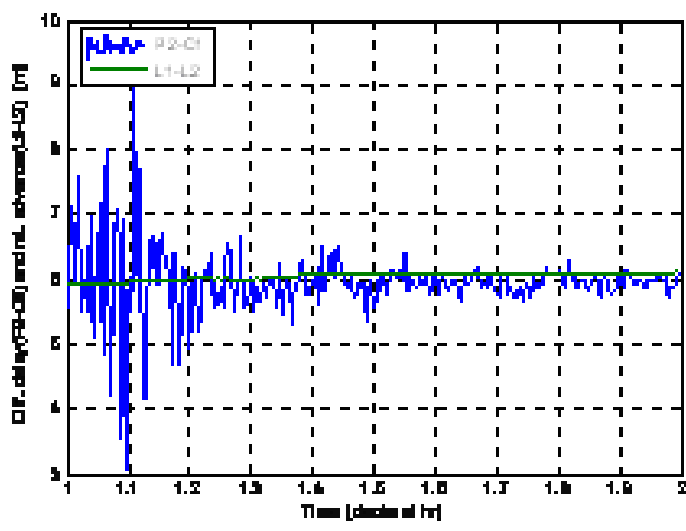

1-2(UT) GPS Satellite PRN 3

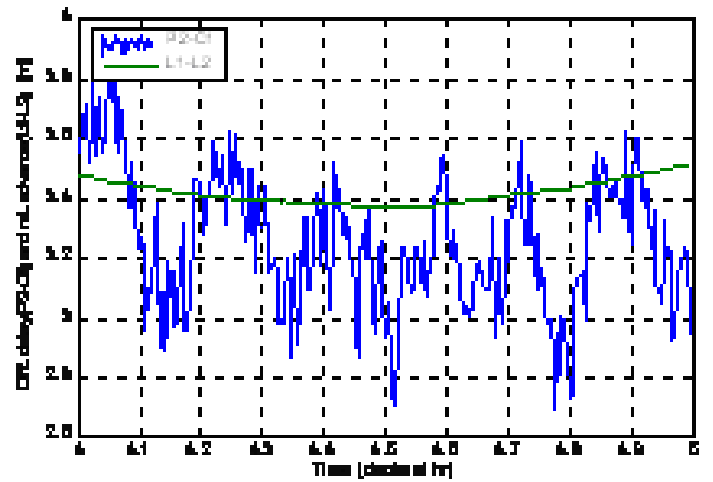

4-5(UT) GPS Satellite PRN 23

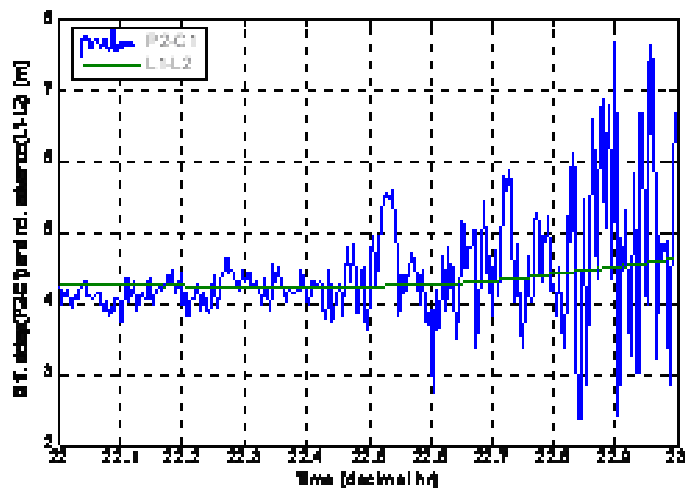

22-23(UT) GPS Satellite PRN 15

Fig. 4: Relative range error computed from the differential carrier phase advance for GPS Satellite PRN 3 (top), PRN 23 (middle) and PRN 15 (bottom) for KTPK Station.

slant value. Figure 6 shows both of TECs computed from this method. 


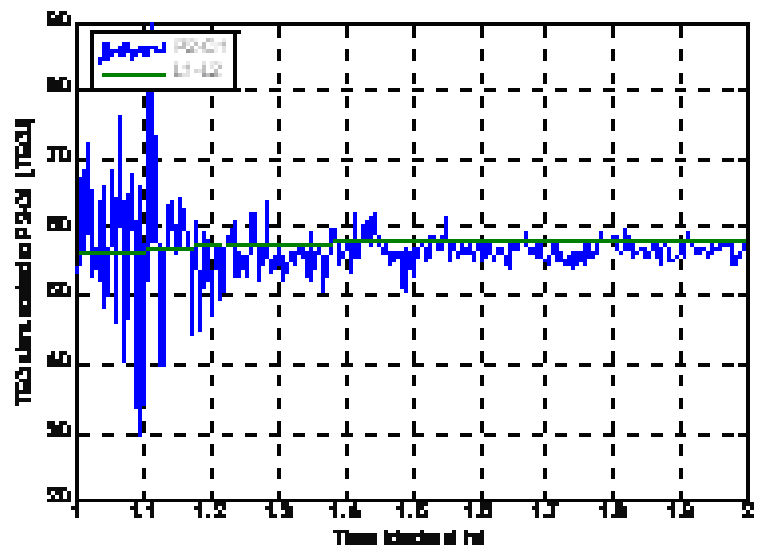

1-2(UT) GPS Satellite PRN 3

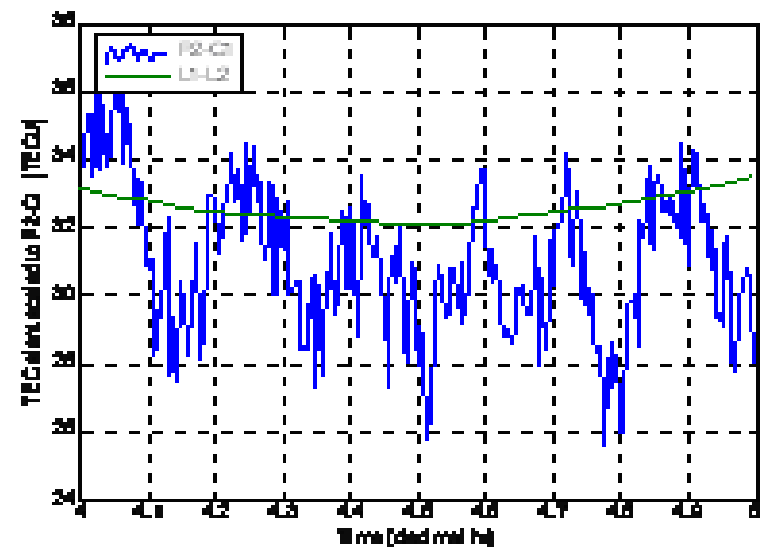

4-5(UT) GPS Satellite PRN 23

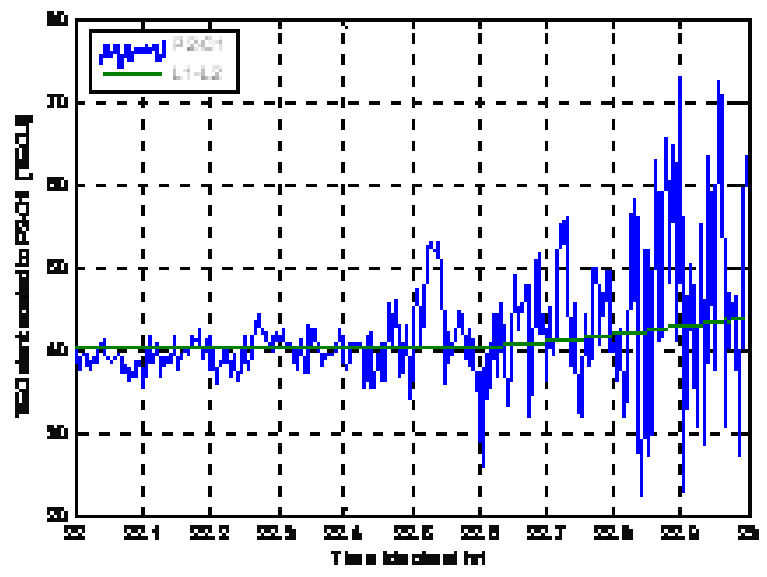

22-23(UT) GPS Satellite PRN 15

Fig. 5: TEC slant scale to (P2- C1) TECU, PRN 3 (top), PRN 23 (middle) and PRN 15 (bottom) for KTPK Station

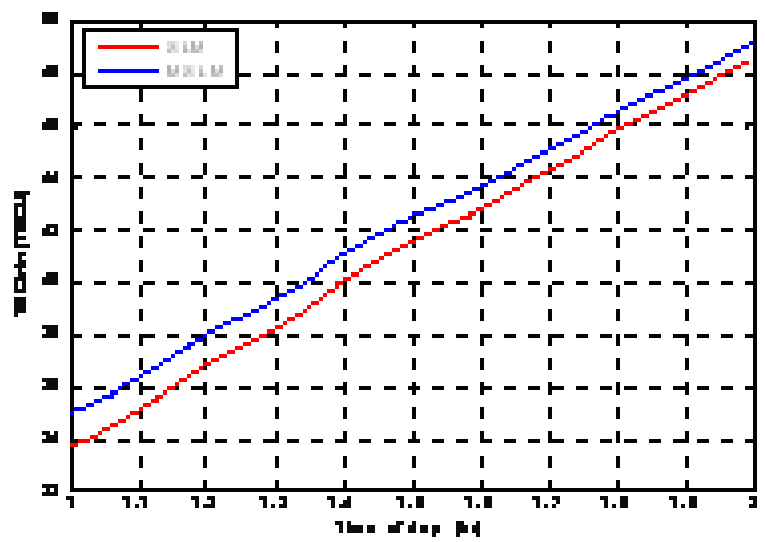

1-2(UT) GPS Satellite PRN 3

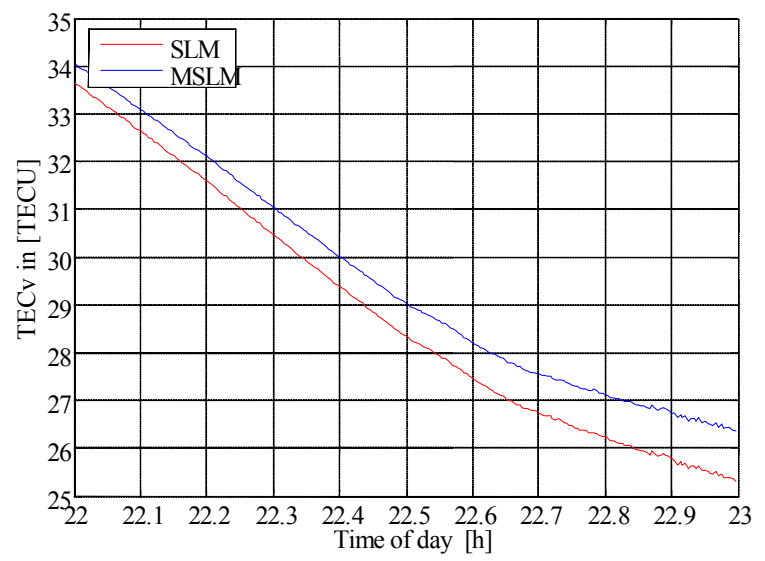

4-5(UT) GPS Satellite PRN 23

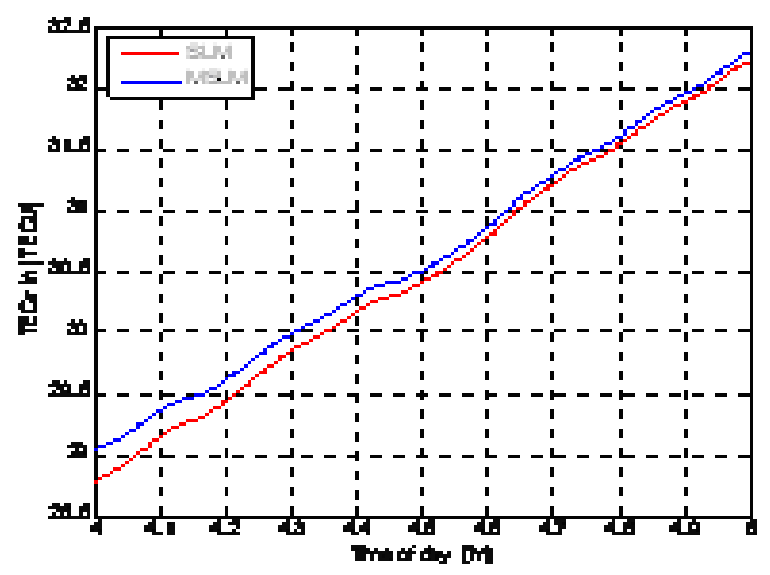

22-23(UT) GPS Satellite PRN 15

Fig. 6: TEC SLM, TEC M-SLM, GPS Satellite PRN 3 (top), PRN 23 (middle) and PRN 15 (bottom) for KTPK Station 


\section{CONCLUSION}

GPS signals can be used to extract ionospheric parameters such as TEC. This research assessed the errors translated from the code-delay to the carrierphase ionospheric observable by the so-called Leveling Process, which was applied to reduce multipath from the data. The leveled carried-phase ionospheric observable is affected by systematic errors, produced by code-delay multipath through the leveling procedure whose effects do not cancel after averaging all the data. A dual-frequency GPS receiver can eliminate (to the first order) the ionospheric delay through a linear combination of L1 and L2 observable.

Several factors affect the quality of real-time ionospheric delay estimation, such as multipath, GPS satellite and receiver L1/L2 differential delays, cycle slips, etc. Dual frequency carrier-phase and code-delay GPS observations are combined to obtain ionospheric observable related to the slant TEC along the satellitereceiver line of sight. This results in the absolute differential delay and the remaining noise is discarded.

The TEC itself is hard to accurately determine from the slant TEC because this depends on the sunspot activity, seasonal, diurnal and spatial variations and the line of sight which includes knowledge of the elevation and azimuth of the satellite etc.

\section{ACKNOWLEDGEMENT}

Jabatan Ukur dan Pemetaan Malaysia (JUPEM) is acknowledged for providing the GPS data for this study. This work was partially funded by Minister of Science, Technology and Innovation (MOSTI) through Science Fund (04-01-02-SF0191). The author would like to express her grateful thanks to Universiti Teknologi Mara (UiTM) for giving the author study leave enabling her to conduct the research.

\section{REFERENCES}

1. Zain, A.F.M. and M. Abdullah, 1999. Initial results of total electron content measurements over arau, Malaysia. In: Proceeding of 4th IEEE Malaysia International Conference on Communications, Melaka, Nov. 17-19, 1: 440-443. $\mathrm{http} / / / \mathrm{www}$.ieeexplore.ieee.org

2. Zain, A.F.M. and M. Abdullah, 2000. Measurements of total electron content variability at Miri, Sarawak: Short term analysis. In: Proceeding of 2nd ICAST, Aug. 15-17, Putrajaya, Malaysia, 2: 1967-1775, http://www.ieeexplore.ieee.org
3. Ho, Y.H., A.F.M. Zain and M. Abdullah, 2002. Hourly variations Total Electron Content, (TEC) for quiet ionosphere over Malaysia. Proceeding of the Annual Workshop National Science Fellowship (NSF) 2001, Jan. 14-15, Petaling Jaya, Malaysia, pp: 77-79. http://www.ieeexplore.ieee.org

4. Tsurutani, B.T., D.L. Judge and F.L. Guarnieri et al., 2005. The October 28, 2003 extreme EUV solar flare and resultant extreme ionospheric effects: Comparison to other Halloween events and the Bastille day event. Geophys. Res. Lett. 32: L003S09. Doi: 10.1029/2004GL021475

5. Fedrizzi, M., R.B. Langley, A. Komjathy, M.C. Santos, E.R. de Paula and I.J. Kantor, 2001. The low-latitude ionosphere: Monitoring its behavior with GPS. Proceedings of ION GPS-2001, Salt Lake City, Institute of Navigation, pp: 2468-2475. http://gause.gge.unb.ca/papers.pdf/longps2001.fedr izzi.pdf

6. Dabas, R.S. and L. Kersley, 2003. Radio tomographic imaging as an aid to modeling of ionospheric electron density. Radio Sci., 38: 10351054. Doi: 10.1029/2001RS002514

7. Pryse, S.E., 2003. Radio tomography a new experimental technique. Surveys Geophys., 24: 138. Doi: 10.1023/a1022272607747

8. Leitinger, R., H.P. Ladreiter and G. Kirchengast, 1997. Ionosphere tomography with data from satellite reception of Global Navigation Satellite System signals and ground reception of Navy Navigation Satellite System signals. Radio Sci., 32: 1657-1670. Doi: 10.1029/97RS01027

9. Gorbunov, M.E., 2002. Ionospheric correction and statistical optimization of radio occultation data. Radio Sci., 37: 17.1-17.9. Doi: 10.1029/2000RS002370

10. Jakowski, N., A. Wehrenpfennig, S. Heise, C. Reigber, H. Lhr, L. Grunwaldt and T. Meehan, 2002. GPS radio occultation measurements of the ionosphere from CHAMP: Early results. Geophys. Res. Lett., 29: 95.1-95.4. Doi: 10.1029/2001GL014364

11. Moeketsi, D.M., W.L. Combrinck, L.A. McKinnell and M. Fedrizzi, 2007. Mapping GPS-derived ionospheric total electron content over Southern Africa during different epochs of solar cycle 23. Adv. Space Res., 39: 821-829. Doi: 10.1016/j.asr.2007.01.065

12. Wanninger, L., 1993. Effects of equatorial. ionosphere on GPS. GPS World, 4: 48-54. http://www.wasoft.de/lit/gpsworld93.pdf

13. Lin, L.S., 2001. Remote sensing of ionosphere using GPS measurements. Proceeding of the 22nd Asian Conference on remote sensing, Nov. 5-9, Singapore, 1: 69-74. www.crisp.nus.edu.sg/ acrs2001/pdf/210LIN.PDF 